\title{
MARXISMO Y NACIONALISMO
}

\author{
Por SANTIAGo SANCHEZ GONZALEZ \\ Universidad Nacional de Educación a Distancia
}

Hallar una explicación coherente del curso de la historia humana es una vieja pretensión, latente o manifiesta, de eruditos, sociólogos y científicos, que sólo parcialmente ha sido satisfecha debido a las dificultades inherentes al objeto investigado. La construcción de una ciencia de las sociedades humanas al modo de las ciencias de la naturaleza, capaz de revelar sin errores el mecanismo del funcionamiento de los entramados sociales, es un intento destinado al fracaso, incluso cuando el ámbito analizado se reduce a una "formación social» concreta.

La afirmación de Engels de que "Marx fue el primero que descubrió la gran ley que rige la marcha de la historia, la ley según la cual todas las luchas históricas, ya se desarrollen en el terreno político, en el religioso, en el filosófico o en otro terrèno ideológico cualquiera, no son en realidad sino la expresión más o menos clara de luchas entre clases sociales...." (1) ha sido desmentida por el desarrollo de los acontecimientos en los últimos ciento veinte años y es un claro ejemplo de filosofia de la historia. Ello, empero, no ha sido obstáculo para que, dada la facilidad con que prosperan las mixtificaciones, (entiendo por mixtificación el engaño colectivo), recientemente se haya sostenido sin el menor pudor intelectual, que "la lucha de clases es el motor de la historia» (2). Dicha tesis, desgraciadamente repetida por el Partido Socialista Obrero Español en su declaración de principios ideológicos (3), fue modificada por el propio Engels, con oca-

(1) Prólogo de F. Engels a la 3. " Ed. alemana de la obra de Marx El 18 Brumario de Luis Bonaparte, pág. 10 de la Edición española de Ariel, Barcelona 1968.

(2) Lous Althusser: Réponse a John-Lewis, F. Maspero, Coll. "Théorien.

(3) XXVII Congreso del P.S.O.E. Edición a cargo de Alfonso Guerra, pág. 116, Ed. Avance, Barcelona 1977. 
sión de la publicación de una de las múltiples ediciones del Manifiesto Comunista, en el sentido de situar históricamente la división en clases y su enfrentamiento en el momento de la disolución de las primitivas comunas.

En todo caso, el largo proceso tergiversador del pensamiento marxiano, es decir, todo aquello que vulgarmente se conoce con el nombre de Marxismoleninismo, ha conseguido transformar en postulados dogmáticos algunas de las tesis marxianas sobre la sociedad industrializada europea de mediados del siglo XIX. No resulta extraño, por tanto, que la izquierda institucionalizada al este y al oeste de los Urales, se nos muestre absolutamente incapaz de solucionar problemas teórico-prácticos actuales como el planteado por el resurgir de los nacionalismos europeos (País Vasco, Bretaña, Córcega, Escocia, por citar algunos.)

¿Cómo es posible integrar los fenómenos nacionalistas en el esquema de la lucha de clases? ¿En qué medida puede explicarse el sentimiento nacionalista y su materialización en acciones concretas, partiendo de la realidad de la lucha de clases en un pais determinado? ¿No constituyen las luchas nacionales un supuesto claro de colaboración entre clases?

En las sociedades de clases, existen elementos dinámicos, desencadenantes de cambios profundos, que no pueden ser reducidos a mera expresión de primero o segundo orden, de la lucha de clases. Más aún, en determinadas épocas históricas, la fuerza de dichos factores es tal que la pertenencia a una clase no pasa de ser una entre las múltiples vinculaciones a las que los hombres se encuentran sometidos en el contexto de cualquier grupo social complejo.

Uno de esos factores es el nacionalismo. Desde sus origenes -que en el marco europeo pueden situarse en el siglo XVIII, el nacionalismo se ha mostrado capaz de superar abismales diferencias entre los miembros del grupo nacional y se ha revelado como una fuerza transformadora de estructuras que en modo alguno puede reclamar la lucha de clases. En terminología marxista, y por lo que respecta a la historia europea de los últimos doscientos años, habría que decir que el nacionalismo ha constituido da contradicción predominante», el elemento determinante de los cambios sociales.

El nacionalismo arranca, en principio de la creencia de pertenecer a un grupo; un grupo que, debido a unos presupuestos comunes -o, al menos, compartidos voluntaria o involuntariamente - presenta una cierta cohesión o unidad y que, en cuanto tal, es o resulta distinto de otros. Cuando la conciencia de esa identidad grupal, de esa afinidad nacional, se alimenta de mitos irracionales, produciendo una clara deformación ideológica de la realidad -que es contemplada desde un prisma fundamentalmente emocional-, tiende a crear la convicción de una superioridad sobre otros grupos semejantes, dando origen al nacionalismo.

El nacionalismo es, sobre todo, una ideología, un conjunto de opiniones o ideas, parcialmente verdaderas, que se traducen en una acción transformadora 
del entorno politico social. El hecho de tratarse de opiniones o afirmaciones parcialmente verdaderas significa que, al mismo tiempo, son parcialmente falsas, es decir, que no corresponden a la realidad, o a toda la realidad. No es posible negar, en una agrupación global humana, la existencia de elementos unificadores como la lengua, la raza, el territorio, las costumbres, la tradición y una serie de lazos económicos y culturales. Sin embargo, deducir de esos componentes homogéneos - a veces, impuestos por la fuerza- la solidaridad de los miembros que los comparten, no pasa de ser una pretensión y, en la mayor parte de los casos, una ficción al servicio de objetivos concretos.

La realidad del sustrato nacional humano ha sido hasta el presente (desde que la nación existe tal y como la entendemos) una realidad antagónica reveladora, no de una voluntad política unitaria, sino de un pluralismo de intereses, afectos y direcciones políticas. Es más, la configuración histórica de la nación en el ámbito europeo occidental ha sido un proceso paralelo al del desarrollo y crecimiento de la formación social más atomizada conocida hasta nuestros dias: la sociedad civil burguesa.

¿Cómo explicar entonces la tremenda fuerza operativa del nacionalismo?

El recurso a la utilización de los textos de los padres fundadores del socialismo cientifico, y de sus continuadores nominales, es inútil. Falta, en el campo marxista, un tratamiento adecuado del fenómeno nacionalista. Para Marx y Engels, Lenin y Stalin, los movimientos nacionalistas tenían sólo interés en la medida en que podían retrasar o acelerar el proceso general revolucionario. De ahí que, ante los problemas nacionales, se limitaran a trazar unas líneas generales de actuación consistentes, en lo fundamental, en apoyar las luchas contra la opresión nacional, subordinar los intereses nacionales a los del proletariado en caso de conflicto y abogar por el internacionalismo de la clase proletaria.

En realidad, tanto Marx como Engels, inmersos en la mentalidad eurocentrista, extrapolaron a escala planetaria las consecuencias extraídas del análisis de la sociedad capitalista europeo-occidental -y más concretamente de la sociedad inglesa $-\mathrm{y}$ esperaron la inminente formación de una uburguesía y de un proletariado, esencialmente los mismos en todos los paises" y de una correlativa revolución mundial que implantaria el comunismo universal (4).

(4) a(...) sólo este desarrollo universal de las fuerzas productivas lleva consigo un intercambio universal de los hombres, en virtud de lo cual, por una parte, el fenómeno de la masa desposeida se produce simultáneamente en todos los pueblos haciendo que cada uno de ellos dependa de las conmociones de los otros (...).

(...) El proletariado sólo puede existir en un plano histórico mundial, lo mismo que el comunismo, sin acción, sỏlo puede llegar a cobrar realidad como existencia histórico-universal». La Ideologia Alemana, págs. 37 y 38, Ed. Grijalbo, S. A. Barcelona 1972.

Abundando en el tema, Carlos Marx afirmó en Trabajo Asalariado y Capital, obra publicada en abril de 1849, «(...) hemos demostrado que todo levantamiento revolucionario tiene necesaria- 
El desarrollo de la humanidad no ha seguido, sin embargo, la pauta de los países europeos más avanzados económicamente. El crecimiento del modo de producción capitalista, a partir de 1860 , lejos de engendrar el enfrentamiento entre dos clases sociales universalmente antagónicas, ha provocado la aparición de un sistema de naciones reproductoras, a nivel grupal, del modelo de la sociedad civil burguesa: disociación de planos nacional e internacional o diplomático (correspondiente mutatis mutandis a la existencia entre los ámbitos privado y público para el hombre-ciudadano); consideración de las otras naciones como simples instrumentos para la consecución de los propios fines (a semejanza de la cosificación realizada por el hombre egoista de las relaciones humanas); $y$, en fin, reconocimiento formal de cada nación o pueblo como miembro de la "comunidad» internacional, en pie de igualdad con las demás naciones o pueblos (al igual que en su día se reconoció la igualdad jurídica entre todos los hombres, sin distinción de clase, raza o religión). Parafraseando a Marx, podriamos decir que la abolición jurídico-política de la «dependencia» internacional, que se produce al afirmar que "todos los pueblos tienen derecho a la libre determinación" (5), no implica la desaparición de la explotación inter-nacional y del imperialismo; más bien, el hecho de que las diferencias reales de recursos y riquezas no se traduzcan en diferencias juridicas, no sólo no acaba con las desigualdades, sino que las presupone. Los organismos internacionales (O.N.U. y asimilados) anulan las diferencias de desarrollo económico, fuerza militar y predominio cultural, cuando declaran que no son diferencias políticas. Sin embargo, permiten al mismo tiempo - ¿acaso podría ser de otra forma? - que la riqueza, el potencial bélico y determinadas culturas actúen a su modo y hagan valer su naturaleza.

En definitiva, lo que pretendo demostrar - cosa que, por otra parte, los hechos históricos han revelado una y otra vez- es que la conciencia de clase, cuando ha llegado a existir, no ha traspasado nunca las fronteras nacionales $y$, aún en esos limitados casos, siempre que ha entrado en conflicto con la conciencia nacional, ha sido derrotada. Baste citar, en este sentido, los desoladores ejemplos de las dos guerras mundiales.

Antes de proseguir conviene, empero, deshacer un posible equivoco que podría derivarse de la lectura de los dos últimos párrafos de esta exposición. Me refiero a la explicación "económica» del problema nacional y del nacionalismo. Creo, sería erróneo considerar que exclusivamente el crecimiento del modo de

mente que fracasar mientras no triunfe la clase obrera revolucionaria, que toda reforma social no será más que una utopia mientras la revolución proletaria y la contrarrevolución feudalista no midan sus armas en una guerra mundialn. Pág. 22, Ed. española de Ricardo Aguilera, Madrid 1968.

(5) Pactos internacionales de Derechos Civiles y Políticos y de Derechos Económicos, Sociales y Culturales. (16 de diciembre de 1966). 
producción capitalista es el culpable, la causa primordial, de todos los nacionalismos, y ello, por más que, desde la órbita marxista, se insista en explicar cualquier ideologia por referencia a unos u otros elementos infraestructurales. Ese recurso puede ser muy válido en el contexto de los recientes movimientos de liberación nacional en los continentes asiático y africano, y siempre que se entienda el nacionalismo como «una reacción local contra la dominación extranjera, o -como- el rechazo continental o racial del imperialismon (6), pero no sirve para comprender fenómenos como el nacionalismo ruso-staliniano de los años treinta...

A fines de 1924, Stalin sostuvo, en franca contradicción con sus afirmaciones anteriores, que Rusia, no obstante el escaso desarrollo de sus fuerzas productivas, podía acceder al socialismo sin necesidad de que la revolución proletaria triunfase en otros países industrialmente más evolucionados. La fórmula escogida para calificar la nueva linea teórica fue la del "socialismo en un solo país». En la PRAXIS, dicha teoría se tradujo en la subordinación de la revolución mundial al liderazgo soviético y en la exaltación del patriotismo ruso en detrimento de los movimientos comunistas de otras naciones. La emergencia del chauvinismo ruso no fue consecuencia de una reacción frente al capitalismo de los países europeos entonces hegemónicos, ni tampoco efecto de la necesidad sentida por la "burguesía" rusa de crear un mercado nacional a medida de sus intereses de clase. Más significativo y relevante fue, a ese respecto, la pretensión staliniana de desprestigiar a Trotski como requisito necesario para asegurar el ejercicio indiscutido del poder -elemento éste que no cabe encuadrar en el marco de los factores infraestructurales, ni puede ser atribuido en modo alguno al sentimiento nacional ruso. El combate dialéctico contra la revolución permanente y el internacionalismo y solidaridad proletarios tuvo que plantearse necesariamente desde sus coordenadas opuestas: nacionalismo ruso y socialismo en un solo país... El golpe de Estado Leninista del 1917, que había pretendido encender la mecha de la explosión socialista mundial, iniciaba así el camino del clásico modelo del despotismo oriental...

El ejemplo referido no constituye, desde luego, la única excepción a la regla capitalismo-engendrador de-nacionalismo; tampoco es el único supuesto en que los intereses de la clase proletaria internacional ceden ante el nacionalismo... por más que éste no pase de ser para los maestros de la práctica-política un instrumento para la conquista del poder.

En la actualidad nos hallamos en presencia de una variante del socialismo nacional que ha encontrado su justificación en las condiciones especificas, politicas, económicas y culturales, de los países europeos ribereños del Mediterráneo.

(6) Víctor C. Ferkiss: Africa en busca de una identidad, pág. 72. Ed. Uteha, México 1967. 
Según los secretarios de los partidos comunistas de Italia, Francia y España, es posible emprender la construcción del socialismo a través de una vía nacional. Obviamente, los presupuestos de tal opción se sitúan en los antípodas del marxismo originario, e, incluso, del marxismo leninismo, como en el caso ruso. $\mathrm{La}$ única pregunta que permanece en el aire es la de si, suponiendo que accedieran al poder los respectivos partidos, los comunistas continuarían la senda socialdemócrata-burgués-imperialista $\mathbf{u}$ optarán por una repetición de la experiencia totalitaria.

Tanto en el supuesto del fenómeno soviético-stalinista, como en el más reciente del eurocomunismo (7), lo que, desde nuestra perspectiva, está bastante claro es el predominio de los intereses nacionales sobre la conciencia de clase, del nacionalismo sobre el clasismo. Poco importa si, en última instancia, lo que se persigue es el mantenimiento del partido y de sus componentes en la esfera anquilosada de las superestructuras, y la conquista de los aparatos burgueses de gobierno. De hecho, la afirmación de una vía nacional peculiar al socialismo supone la negación de una vía universal (ala acción coincidente de los pueblos dominantes", que diria Marx) y, lo que es más importante, el desconocimiento de la inter-dependencia de las unidades nacionales y de las vinculaciones reales con los grandes monopolios internacionales. Parece como si fuera necesario explicarles a los eurocomunistas que la libertad, independencia y pleno desarrollo de cada agrupación humana (sea ésta, pueblo, nación, región o provincia) está, sobre todo desde que estamos viviendo por primera vez la Historia Universal, absolutamente condicionada por las correlativas libertad, independencia y pleno desarrollo de las demás «agrupaciones globales humanas». Parece, en fin, que debemos recordar a los materialistas históricos que no puede existir socialismo en medio de las crisis económicas, rodeados de pobreza, sin un desarrollo tremendo de las fuerzas productivas: el socialismo, antes que libertad o igualdad, es por encima de todo, ABUNDANCIA.

(7) La práctica del Eurocomunismo - si por tal vocablo se entiende entre otras cosas la participación y aceptación por los partidos comunistas de las reglas del juego democrático-burgués se remonta en Francia e Italia a la posguerra. En cuanto a su elaboración teórica partidista, los origenes están perfectamente delimitados en el «policentrismo» de Palmiro Togliatti. Y si lo que se pretende con el Eurocomunismo es fundamentalmente, señalar la línea de no retorno al sometimiento al partido comunista de la Unión Soviética entonces, no cabe ya la menor duda de que estamos ante un nacionalismo comunista. 


\section{BIBLIOGRAFIA}

AMIN, Samir: La.Nation Arabe, nationalisme et lutte de classes. Editions de Minuit, París 1976.

BLOOM, Salomón F.: El mundo de las naciones. El problema nacional en Marx. Siglo XXI, Argentina Eds. S. A. Buenos Aires 1973.

DAVIS, Horace B.: Nacionalismo y Socialismo. Edic. Península, Barcelona 2. ${ }^{\mathrm{a}}$ ed. 1975.

DEUTSCH, Karl W.: El Nacionalismo y sus alternativas. Ed. Paidós, Buenos Aires, 1971.

ENEA SPILIMBERGO, Jorge: La Cuestión Nacional en Marx. Edics. Octubre, 3. ${ }^{a}$ ed. Buenos Aires, 1974.

GARATE, G.: Marx y los nacionalismos separatistas. Ed. Angel Gárate, Bilbao 1974.

HERRERO DE MIÑON, M.: Nacionalismo y constitucionalismo. Ed. Tecnos, Madrid 1977.

KOHN, Hans:' Historia del Nacionalismo. F. C. E. $1 .^{\mathrm{a}}$ ed. en español. México 1949.

NIN, Andreu: Los movimientos de emancipación nacional. Ed. Fontamara, Barcelona 1977.

\section{Artículos}

BARCELO, M.: "Una nota sobre la cuestión nacional española», en Cuadernos Anagrama (145). Ed. Anagrama, Barcelona 1977.

BLAUT, J.: «El marxismo y la cuestión nacional», en Monthly Review, págs. 2038, octubre 1977.

CARRERE D'ENCAUSSE, H.: “Comunismo y Nacionalismo variedad proletaria y Diversidad Nacional", en Cuadernos Anagrama, Ed. Anagrama, 1977.

NAIRN, Tom: «Marxism and the modern Janus», en New Left Review, núm. 94, nov-dec. 1975 , págs. 3 y 29.

RODENAS, Pablo: «Nacionalidad, nación e imperialismo» en El Carabo, número 5, págs. 103-130. Madrid, marzo-abril, 1977. 